\title{
DESIGN AND SIMULATION OF A TUNABLE FREQUENCY MICROSTRIP PATCH ANTENNA
}

\author{
Akansha Tandon ${ }^{1}$, B.R.Dutta ${ }^{2}$, Yogesh K. Bhomia ${ }^{3}$ \\ ${ }^{I}$ Student, ${ }^{2}$ HOD EC Dept, SRMS College of Engg, and Tech., Bareilley, India \\ ${ }^{3}$ Principal, Universal Technical College, Jaipur, India
}

\begin{abstract}
This paper presents an evaluation of frequency reconfigurable patch antennas for X-band, using PIN diode as a switch. A pin diode is incorporated in the slot etched on rectangular patch antenna. The frequency band selectivity can be achieved by controlling the state of switch inserted in the antenna. We are using IE3D simulation software for designing and analysis. We have discussed and analyzed the performance of unslotted Rectangular Microstrip patch antenna and slotted rectangular patch antenna with PIN diode in ON and OFF states.
\end{abstract}

Keyword: Microstrip Antenna, Return Loss, Radiation pattern, IE3D.

$* * *$

\section{INTRODUCTION}

In wireless communication applications, the demand for low profile compact size planar antenna is increasing day by day. The light weight, small size handheld wireless devices design challenges never stops. Various types of low-profile elements have recently been developed and they fairly efficient radiators that can be easily manufactured at low cost. The conventional microstrip patch is not a good candidate for wireless applications, due to certain disadvantages as narrow bandwidth. Therefore, more unusual approaches are investigated for multiband antenna with reduced size operation. The main goal is to design antennas for wireless communication applications where the space value of the antenna is quite limited while it reserves the characteristics of multiband, light weight, low cost and robustness.

Reconfigurable antennas are similar to the conventional antenna but one or more of its specification or characteristics could be adjusted or tuned using RF switches/MEMs or variable capacitors/inductors. They have four types: 1Frequency reconfiguration, 2-Polarization diversity, 3Radiation pattern steering, 4- Combination of the three previous types.

\section{FREQUENCY-RECONFIGURABLE}

\section{ANTENNAS}

The advantage of a frequency reconfigurable antenna is that it allows a single radio device to operate at multiple frequencies. For example, a tuning method can be used into multiple bands for mobile applications. The radiation patterns of such antennas remain unchanged as the frequencies are tuned from one band to another. In designing a frequency reconfigurable antenna, a single antenna will be able to tune from lower frequency to higher frequency bands by reusing the real estate in the antennas or tune in and out of different antenna sections. Most resonant type antennas tune the effective electrical length to achieve frequency reconfigurability.

Switching and / or tuning takes place with the aid of PIN diode or MEMs switches or varactors adopted with antenna structure. PIN diodes are reliable and experience high switching speed but introduce nonlinearity and need complex bias circuitry to be integrated with the antenna. On the other hand MEMs have lower insertion loss, easier in integration (no need for biasing circuit), less static power consumption and have higher linearity, but it needs high static bias voltage. According to the various advantages of reconfigurable antennas they are currently part of modern wireless communication systems such as (DCS/GSM/WCDMA/ Bluetooth/WLAN), handheld GPS and other navigation systems and MIMO systems.

\section{ANTENNA STRUCTURE AND DESIGN}

The objective is to design, simulate and analyze a tunable MSA with rectangular patch and operating frequencies in the range (9 to 13) GHz. This would be accomplished by using substrate layer of GML1000 substrate with dielectric constant $\varepsilon_{\mathrm{r}}=3.2$ and almost $0.762 \mathrm{~mm}$ thick.

First, we will start with conventional rectangular Microstrip patch antenna and calculate the length and width of the patch, width of the feed line to feed patch and length and width of the half-quarter wave transformer used as a matching network using standard rectangular Microstrip antenna design equations for resonance at $10 \mathrm{GHz}$. In order to get reconfigurability in frequency, a pin diode is added to the slot etched on the rectangular patch. By controlling the PIN diode 
bias voltage, the antenna can be switch between two different frequencies.

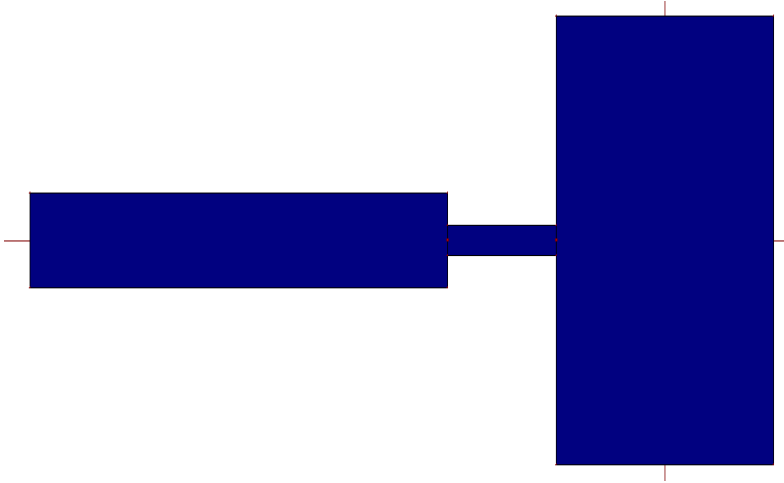

Fig. 1 Rectangular Microstrip patch antenna

\section{EXPERIMENTAL RESULTS}

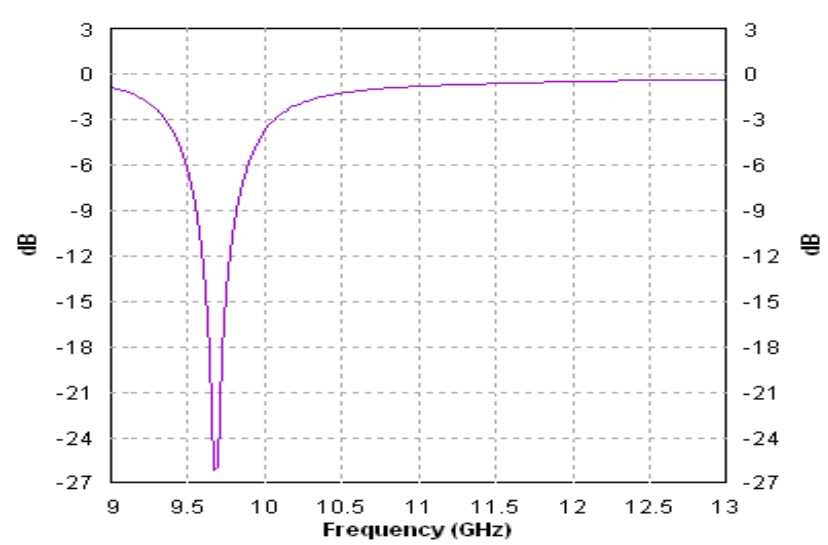

Fig. 2 Return loss v/s Frequency plot of rectangular MPA (RMPA)

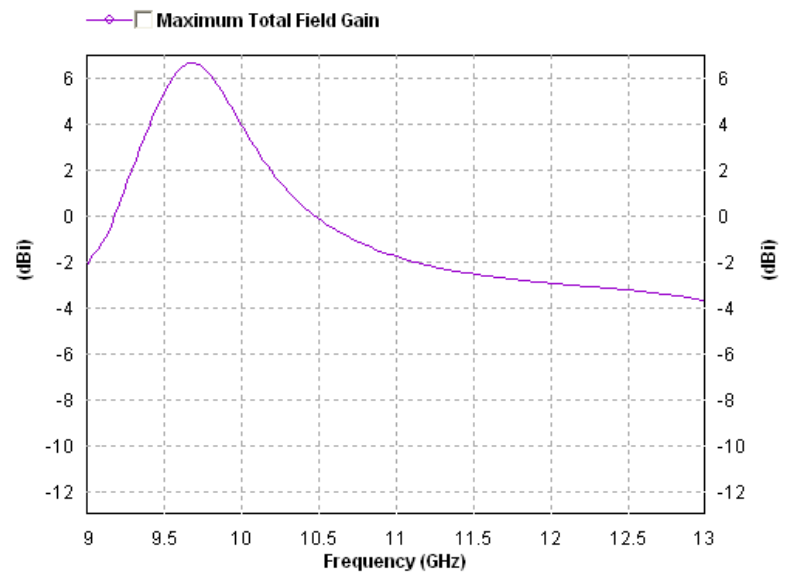

Fig. 3 Gain v/s Frequency plot of RMPA

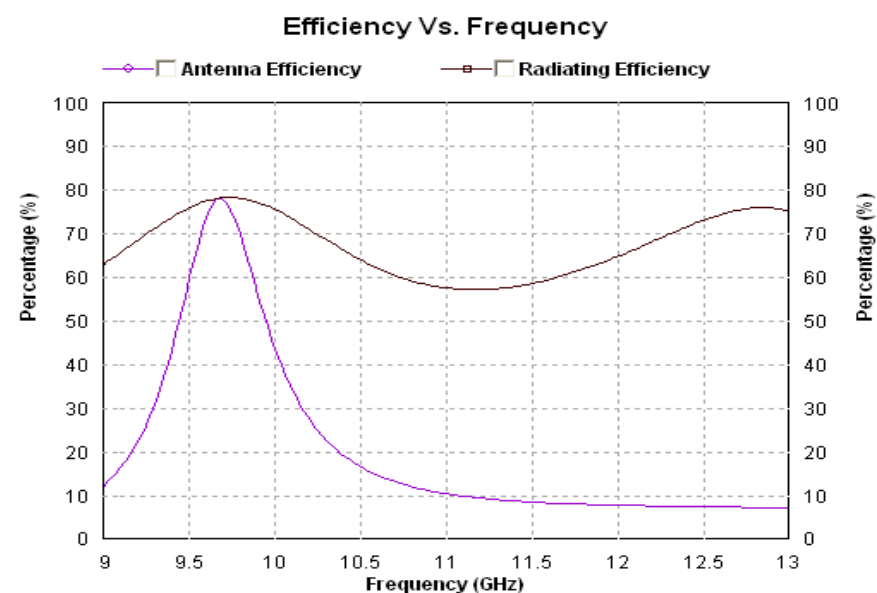

Fig. 4 Efficiency v/s Frequency plot of RMPA

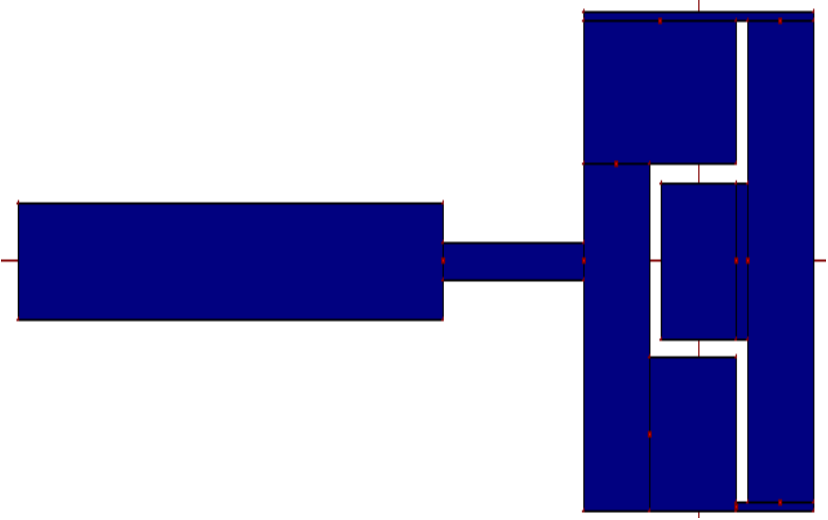

Fig. 5 RMPA with slot

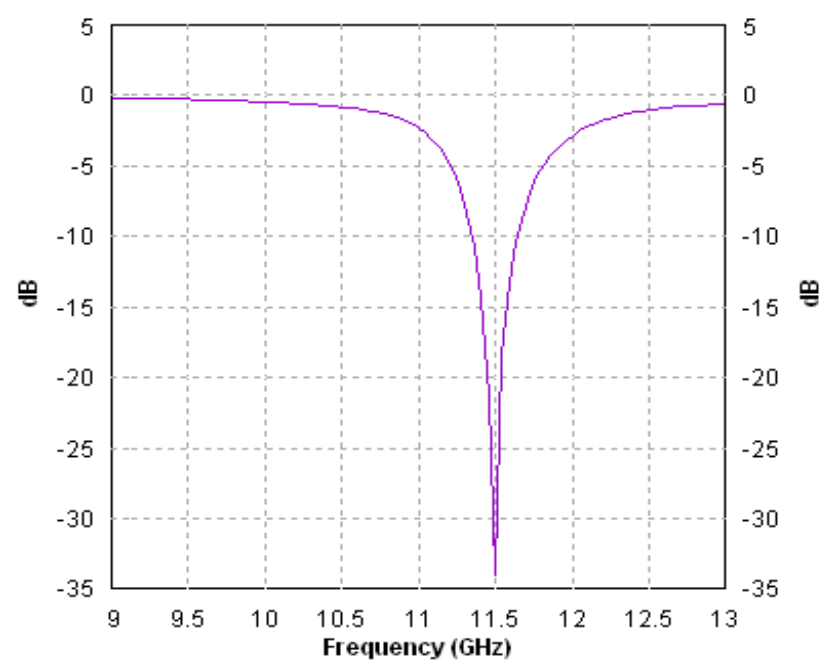

Fig. 6 Return loss v/s Frequency plot when PIN diode is OFF 


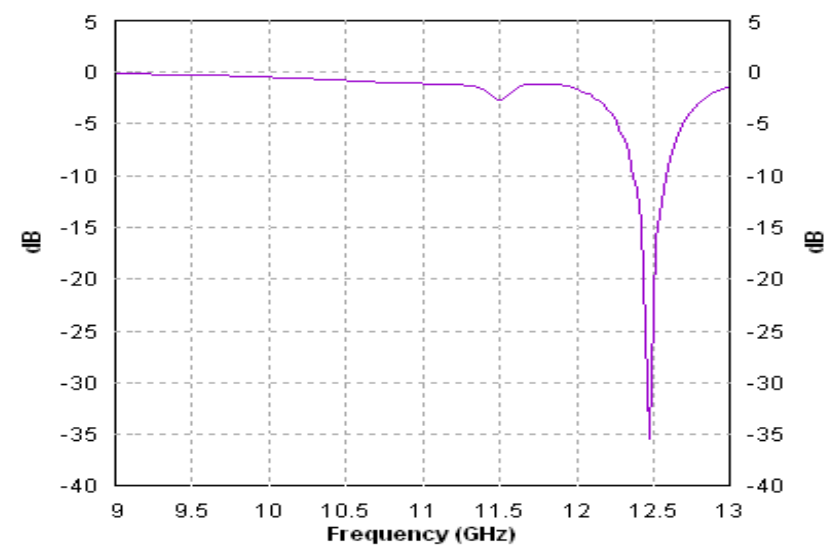

Fig.7. Return Loss When PIN diode is ON

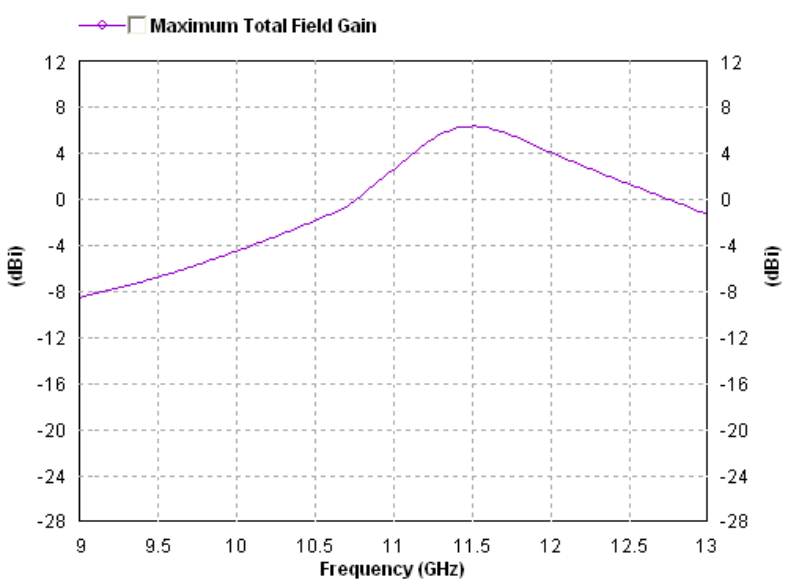

Fig.8. Gain v/s Frequency plot when PIN diode is OFF

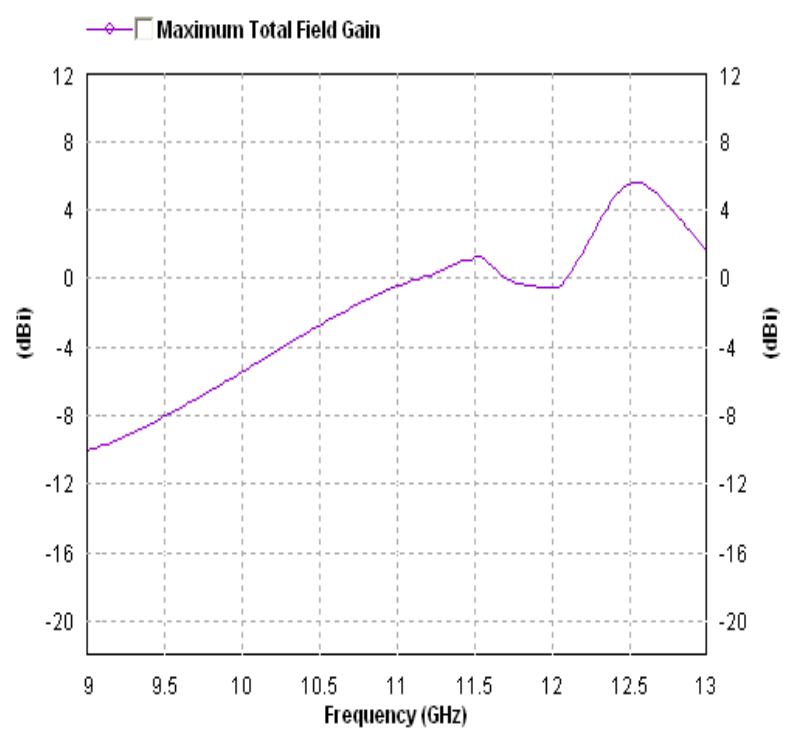

Fig. 9 Gain v/s Frequency plot when diode is ON

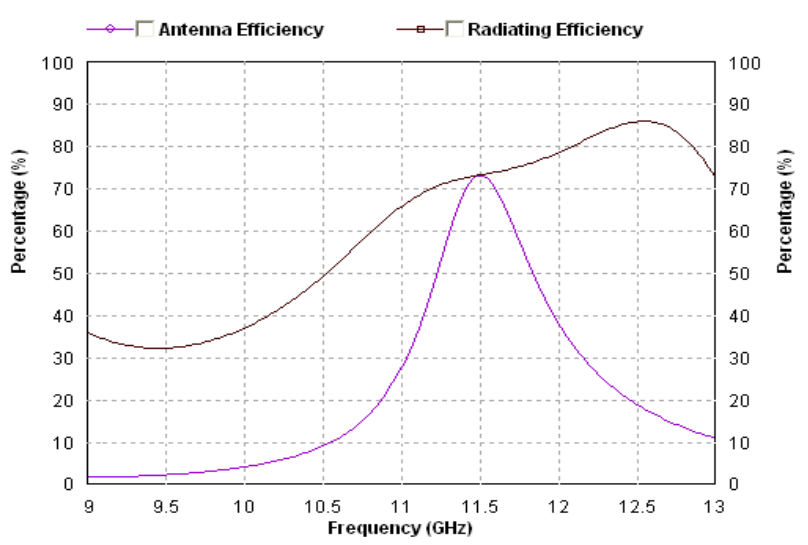

Fig.10 Efficiency v/s Freqency plot when PIN diode is OFF

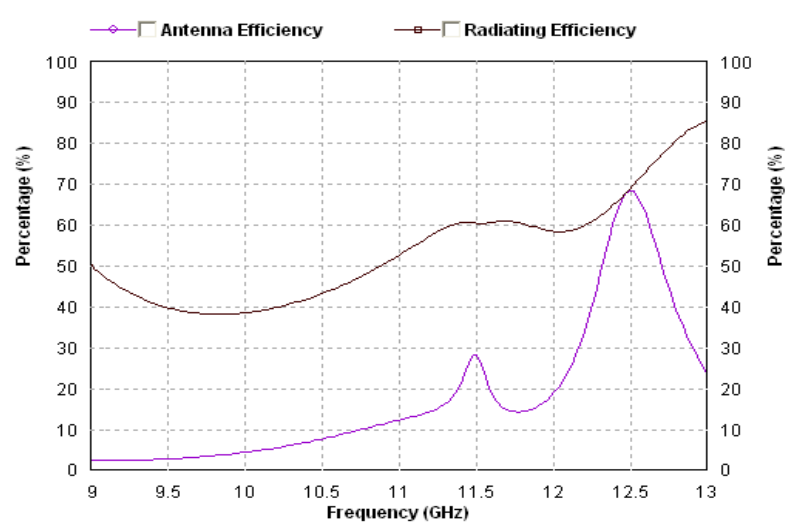

Fig 11 Efficiency v/s Frequency plot when diode is On

\section{COMPARISON}

Table 3.3 shows the comparison between the rectangular patch antenna, slotted patch antenna when PIN diode is switched $\mathrm{OFF}$ and $\mathrm{ON}$

\begin{tabular}{|l|l|l|l|}
\hline Parameters & $\begin{array}{l}\text { Simple } \\
\text { MPA }\end{array}$ & $\begin{array}{l}\text { Slotted } \\
\text { MPA when } \\
\text { diode is } \\
\text { OFF }\end{array}$ & $\begin{array}{l}\text { Slotted } \\
\text { MPA when } \\
\text { diode is ON }\end{array}$ \\
\hline $\begin{array}{l}\text { Resonant } \\
\text { Frequency }\end{array}$ & $9.67 \mathrm{GHz}$ & $11.49 \mathrm{GHz}$ & $12.47 \mathrm{GHz}$ \\
\hline $\begin{array}{l}\text { Impedance } \\
\text { Bandwidth }\end{array}$ & $22.8 \%$ & $32 \%$ & $25 \%$ \\
\hline VSWR & 1.104 & 1.014 & 1.03 \\
\hline Gain & $6.6 \mathrm{dBi}$ & $6.28 \mathrm{dBi}$ & $6 \mathrm{dBi}$ \\
\hline Efficiency & $78 \%$ & $73 \%$ & $68.6 \%$ \\
\hline
\end{tabular}




\section{CONCLUSIONS}

For rectangular patch antenna the first design had a $228 \mathrm{MHz}$ bandwidth ( $2.36 \%$ of center frequency) whereas when a PIN diode is incorporated in the slot and is switched OFF the bandwidth is increased to $320 \mathrm{MHz}$, which gives a percent of bandwidth to centre frequency of $2.79 \%$ that means the bandwidth improvement approximately $92 \mathrm{MHz}$. Whereas when the PIN Diode is switched ON the bandwidth is decreased to $250 \mathrm{MHz}$ which gives percent of bandwidth to center frequency of $2.01 \%$ approximately.

\section{REFERENCES}

[1]. James, J.R. and Hall, P.S.: 'Handbook of Microstrip Antennas' (Peter Peregrinus)

[2]. Constantine A. Balanis : 'Antenna Theory, Analysis and Design' (John Wiley \& Sons)

[3]. Lu JH, Tang CL, Wong KL, 'Novel dual-frequency and broadband designs of the slot-loaded equilateral Triangular Microstrip Antenna' IEEE Trans. Antennas Propag. 2000;48;1048-54.

[4]. Row JS. 'Dual-frequency triangular planar inverted-f Antenna' IEEE Tran Antennas Propag 2005;53;874-6.

[5]. Kai-Fong Lee, Kwai- Man Luk, Jashwant S. Dahele, 'Characteristics of the Equilateral Triangular Patch Antenna' IEEE Tran. Antennas Propag.1988;36;1510.

[6]. C. L. Mak, K. M. Luk, K. F. Lee, ' Wideband Triangular Patch Antenna' IEE. Proc. Microwave Antennas Propag. 1999.

[7]. Shan-Cheng Pan and Kin- Lu Wong, 'Dual Frequency Triangular Microstrip Antenna with Shorting Pin' IEEE Tran. Antennas Propag.1997;45;1889

[8]. D.M. Pozar and D. H. Shaubert, 'Microstrip Antennas : The Analysis and Design of Microstrip Antenna and Array' IEEE Press,Inc., 1980.

[9]. I. J. Bahl and P. Bhartia, 'Microstrip Antennas, Artech House, Dedham, MA, 1980.

[10]. IE3D [1] by Zeland software Inc. 